\title{
Numerical Simulation and Performance Assessment of a Nanoparticle Enhanced Vapour Compression Refrigeration System
}

\author{
Moradeyo K. Odunfa*, Oluwaseyi D. Oseni \\ Department of Mechanical Engineering, University of Ibadan, Ibadan, Nigeria \\ Email: odunfaj@yahoo.com, ${ }^{\star}$ m.odunfa@mail.ui.edu.ng, ${ }^{\star}$ Nickest2005@yahoo.com
}

How to cite this paper: Odunfa, M.K. and Oseni, O.D. (2021) Numerical Simulation and Performance Assessment of a Nanoparticle Enhanced Vapour Compression Refrigeration System. Journal of Power and Energy Engineering, 9, 33-49.

https://doi.org/10.4236/jpee.2021.911002

Received: April 20, 2021

Accepted: November 16, 2021

Published: November 19, 2021

Copyright (c) 2021 by author(s) and Scientific Research Publishing Inc. This work is licensed under the Creative Commons Attribution International License (CC BY 4.0).

http://creativecommons.org/licenses/by/4.0/

\begin{abstract}
Cooling in industrial production and refrigeration of perishable and nonperishable products is common practice throughout the world. Research studies have been conducted both experimentally and numerically to simulate Vapor Compression Refrigeration System (VCRS) and its performance respectively, however, experimental procedure often seems to be expensive and time-consuming to carry out due to the function of many variables. This study was therefore designed to numerically simulate the performance assessment of a nanoparticle enhanced VCRS. A numerical model of a vapor compression refrigeration system was developed using standard refrigeration equations on each of the major components of the refrigeration system such as compressor, evaporator, condenser and expansion valve. The model was then simulated on a MATLAB platform with a CoolProp installed packages via Python under two different simulation cases. In the first case, the mass fractions were varied for $\mathrm{CuO}, \mathrm{TiO}_{2}$ and $\mathrm{Al}_{2} \mathrm{O}_{3}$ nanoparticles while their densities remained constant and a reversed condition was investigated for the second case. The results showed that both the refrigerating effect and the Coefficient Of Performance (COP) of the system increase as both the mass fraction and density of all the nanoparticles increases. It also shows that the compressor work decreases as both the mass fraction and density of all the nanoparticles were increased. On comparing the computational and numerical analysis results, the study established no significant difference in terms of $\mathrm{COP}$ and the use of nanoparticles were found to have improved the COP of the system.
\end{abstract}

\section{Keywords}

CoolProp, Coefficient of Performance, Vapour Compression Refrigeration, Mass Fraction 


\section{Introduction}

More than a century ago, researchers have initiated the efforts to enhance inherently poor thermal conductivity of liquids by adding solid particles in base fluids. Earlier studies used millimeter or micrometer solid particles, which led to problems such as rapid settling of solid particles, clogging, surface abrasion \& high-pressure drop, limiting their practical applications. Nanofluids have good potential to overcome these problems. In the last decade, the number of published articles mentioning nanoparticles has increased significantly in refrigeration field. Taiwo et al. [1] investigated the effect of Nanoparticles on the coefficient of performance, power consumption, thermal conductivity, viscosity and heat transfer of refrigerants. The study showed that the application of Nanoparticles as additives in refrigerant and lubricant in Vapor Compression Refrigeration System is favorable and promising. The authors concluded that Nano refrigerants are expected to be the future refrigerants to be adopted by VCRS manufacturers. Pitchia et al., in 2019 [2] conducted experimental examination of a vapor pressure refrigeration framework by utilizing nano refrigerant (R290/ $\mathrm{R} 600 \mathrm{a} / \mathrm{Al}_{2} \mathrm{O}_{3}$ ) to improve the framework execution and decrease the power utilization. The outcomes demonstrate that by including the nanoparticles $\left(\mathrm{Al}_{2} \mathrm{O}_{3}\right)$ to the other refrigerant blend (R290/R600a), the coefficient of execution is somewhat expanded while control utilization by blower is marginally diminished. The nano refrigerant $\left(\mathrm{R} 290 / \mathrm{R} 600 \mathrm{a} / \mathrm{Al}_{2} \mathrm{O}_{3}\right)$ can work ordinarily and proficiently in coolers. Contrasted and icebox with unadulterated (R290/R600a) as working liquids, $0.3 \mathrm{~g} / \mathrm{L}$ convergences of $\left(\mathrm{R} 290 / \mathrm{R} 600 \mathrm{a} / \mathrm{Al}_{2} \mathrm{O}_{3}\right)$ can spare $29.33 \%$ vitality utilization. The authors concluded that the residential cooler execution will be improved by including the nanoparticles $\left(\mathrm{Al}_{2} \mathrm{O}_{3}\right)$ to other refrigerant blend (R290/R600a). In 2020, Vipin Nair et al. [3] conducted an experimental analysis on $\mathrm{R} 134 \mathrm{a}$ vapour compression refrigeration system using nano-oil. In their work, $\mathrm{Al}_{2} \mathrm{O}_{3}$ nanoparticles were used for the preparation of the nano-oil. The COP of the system was found to be improved by as much as $6.5 \%$ due to nano-oil and the degree of sub-cooling in the condenser of the system was enhanced by Nano-oil.

Senthilkumar et al. in 2021 also investigated the performance of R600a vapour compression system using $\mathrm{CuO} / \mathrm{Al}_{2} \mathrm{O}_{3}$ hybrid nanolubricants [4]. Three different nanolubricant concentrations of $0.2,0.4$ and $0.6 \mathrm{~g} / \mathrm{L}$ were considered in the study with $70 \mathrm{~g}$ of R600a refrigerant. The result established an enhancement of COP up to $27 \%$ from 1.17 to 1.6 and increase of cooling capacity up to $20 \%$ from 160 to $200 \mathrm{~W}$ and reduction in power utilized by the compressor up to $24 \%$ from 158 to $120 \mathrm{~W}$; hence $\mathrm{CuO} / \mathrm{Al}_{2} \mathrm{O}_{3}$ hybrid nanolubricant refrigerator can be employed as better substitute for R134a refrigerator. In 2011, Subramani and Prakash [5] studied the $\mathrm{R} 134 \mathrm{a} / \mathrm{Al}_{2} \mathrm{O}_{3}$ Nano refrigerant and found that there is an enhancement in COP while nanoparticles were added to the system. They also determined the system's COP theoretically for both R134a and $\mathrm{R} 134 \mathrm{a} / \mathrm{Al}_{2} \mathrm{O}_{3}$. They found that the COP of cycles that use R134a increases by $10.11 \%$ while the 
$\mathrm{R} 134 \mathrm{a} / \mathrm{Al}_{2} \mathrm{O}_{3}$ mixture used in the actual refrigeration cycle and enhancement ratio was $9.74 \%$ when COP determined theoretically. Sajumon et al., in 2013 found through his study that Nanolubricants show higher viscosity and smaller friction co-efficient [6]. It also results in the less power consumptions with high heat transfer rates and Co-Efficient of Performance. Babarinde et al., in their work investigated R600a in MWCNT-nanolubricant $(0.4 \mathrm{~g} / \mathrm{L}$ and $0.6 \mathrm{~g} / \mathrm{L})$ as a drop in replacement for R134a refrigerant in a household refrigerator system with varied mass charge of R600a (50,60 and $70 \mathrm{~g}$ ) [7]. The study established a better performance in terms of COP, power consumption and cooling capacity hen compared with R134a in the system, lower evaporator temperature of $-11^{\circ} \mathrm{C}$ and power consumption of $0.0639 \mathrm{Kw}$ and highest COP in the system; hence R600a/MWCNT-nanolubricant drop in is a better replacement for R134a in the household refrigerator. In 2020, Babarinde et al. also investigated the use of grapheme to enhance the performance of R600a vapour compression refrigeration system [8]. Graphene nanolubricant was prepared using graphene nanoparticles dispersed in the based lubricant. Different samples of grapheme nanolubricant concentrations were investigated. The study established better performance of graphene nanolubricant when compared with the base lubricant in terms of pull-down time, COP, power consumption and cooling capacity. Kedzierski, in 2012 investigated the pool boiling of R134a/diamond/RL68H nanorefrigerant and reported a $98 \%$ enhancement in boiling heat transfer for the $0.5 \%$ nanolubricant mass fraction compared to R134a/polyester while the enhancement of the $2 \%$ nanolubricant mass fraction was $19 \%$ [9]. According to Juan et al., in 2010 , in spite of the extensive number of studies on the enhancement of thermal conductivity and heat transfer mechanism of nanofluids, little has been done yet on the effect of such enhancements on the overall properties and performance of a system [10]. Thus, the present study deals with the numerical simulation and performance assessment of nanoparticle enhanced vapor compression refrigeration system.

\section{Methodology}

The vapor-compression refrigeration is a variety of refrigeration. Generally, the system of vapor-compression refrigeration as shown in Figure 1 consists of a condenser, an expansion valve, an evaporator, and a compressor. The vapor-compression refrigeration cycle consists of four processes:

(1-2) compressing refrigerant in compressor isentropically;

(2-3) condensation at constant pressure;

(3-4) adiabatic expansion in the expansion valve;

(4-1) evaporation at constant pressure.

The evaporation of the refrigerant occurs at a constant pressure during process (4-1) in the evaporator. The refrigerant at the inlet of the evaporator is vaporized by removing heat from the area desired to cool. Saturated vapor at point 1 goes into the compressor at low pressure and is exposed to a reversible 


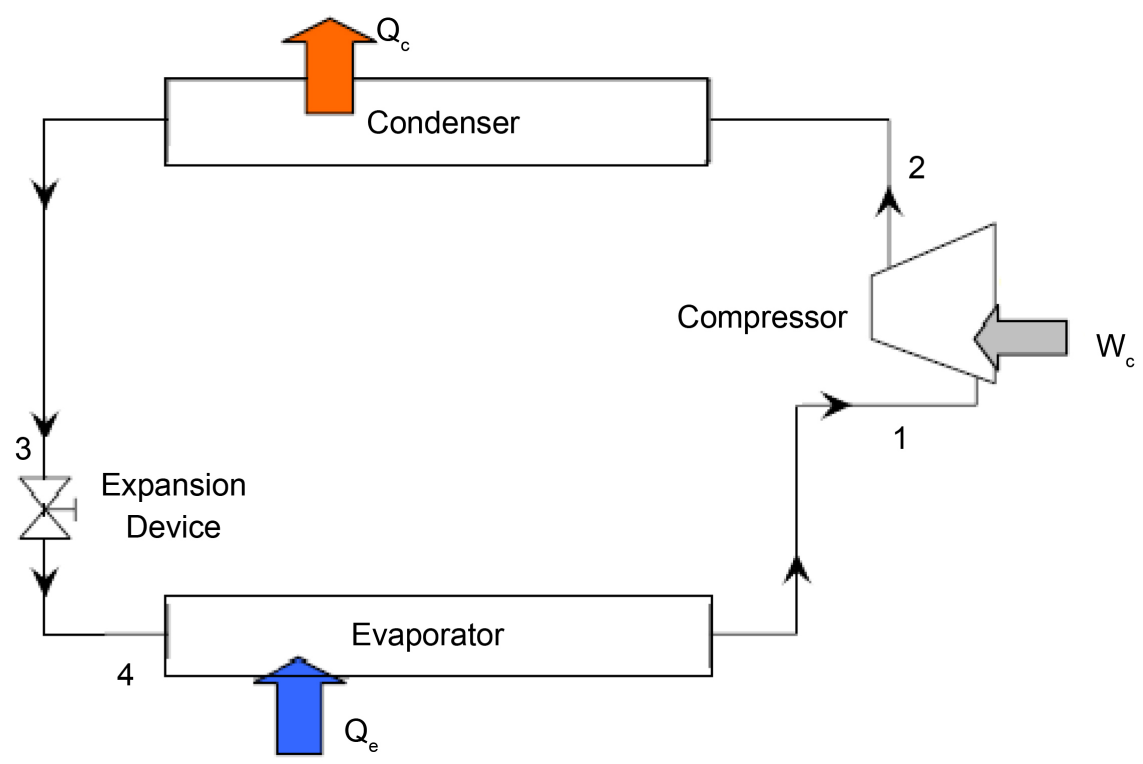

Figure 1. Physical and mathematical model.

isentropic compression during the process from 1 to 2 . During process (2-3), while the heat is rejected in the condenser at a constant pressure, the working fluid changes to a saturated liquid when exiting the condenser. Refrigerant at point 1 is saturated vapor at the evaporator temperature and at point 3 is saturated liquid at the condenser temperature. The working fluid at the exit of the expansion valve enters the evaporator, and the cycle is completed. Completely vaporized refrigerant enters the compressor, and its pressure and temperature increase during the compressing process. The working fluid at the condenser outlet is saturated liquid.

The system's properties of interest are calculated using standard refrigeration Equations (1)-(10) as follows:

- Heat transfer rate of the evaporator or refrigerating effect (RE)

$$
q_{e}=h_{1}-h_{4}
$$

- Compressor work

$$
w_{\text {comp }}=h_{2}-h_{1}
$$

$\eta_{i s e}=\frac{h_{2 s}-h_{1}}{h_{2 a}-h_{1}} \quad$ (Isentropic efficiency)

- Heat transfer rate of the condenser

$$
q_{c}=h_{2}-h_{3}
$$

- C.O.P $=\frac{q_{e}}{w_{\text {comp }}}$

The components can also be analyzed in terms of mass flow rates and specific heat as shown below;

1) Compressor

$$
\dot{W}_{\text {comp }}=\dot{m}_{1} c_{p, n f}\left(T_{2}-T_{1}\right)
$$




$$
\dot{m}_{1}=\dot{m}_{2}
$$

where $\dot{W}_{\text {comp }}=$ Power input into the compressor,

$c_{p, n f}=$ Specific heat of Nanofluid at constant pressure,

$\dot{m}_{1}$ and $\dot{m}_{2}$ are mass flow rates,

$T_{1}$ and $T_{2}$ are temperatures at the compressor inlet and exit respectively.

\section{2) Condenser}

$$
\begin{gathered}
\dot{Q}_{C}=\dot{m}_{2} c_{p, n f}\left(T_{3}-T_{2}\right) \\
\dot{m}_{2}=\dot{m}_{3}
\end{gathered}
$$

where $\dot{Q}_{C}=$ rate of heat removal at the condenser,

$c_{p, n f}=$ Specific heat of Nanofluid at constant pressure,

$\dot{m}_{2}$ and $\dot{m}_{3}$ mass flow rates,

$T_{2}$ and $T_{3}$ are temperatures at the condenser inlet and exit respectively.

\section{3) Capillary}

$$
\begin{gathered}
T_{4}=T_{3} \\
\dot{m}_{4}=\dot{m}_{3}
\end{gathered}
$$

where $\dot{m}_{3}$ and $\dot{m}_{4}$ mass flow rates.

$T_{3}$ and $T_{4}$ are temperatures at the capillary inlet and exit respectively.

\section{4) Evaporator}

$$
\begin{gathered}
\dot{Q}_{e}=\dot{m}_{4} c_{p, n f}\left(T_{1}-T_{4}\right) \\
\dot{m}_{4}=\dot{m}_{3}
\end{gathered}
$$

where $\dot{Q}_{e}=$ rate of heat removal at the evaporator,

$c_{p, n f}=$ Specific heat of Nanofluid at constant pressure,

$\dot{m}_{4}$ and $\dot{m}_{3}=$ mass flow rates,

$T_{4}=$ Inlet temperature of refrigerant,

$T_{1}=$ outlet temperature of refrigerant.

$$
\text { C.O.P }=\frac{\dot{Q}_{e}}{\dot{W}_{c o m p}}
$$

While the Nano refrigerant's thermo physical properties of interest are calculated as follows:

- Density

$$
\rho_{N F}=\omega_{n} \rho_{P}+\left(1-\omega_{n}\right) \rho_{P R}
$$

For the purpose of this work (theoretical modeling), we shall make use of three nanoparticles $\left(\mathrm{CuO}, \mathrm{TiO}_{2}\right.$ and $\left.\mathrm{Al}_{2} \mathrm{O}_{3}\right)$ with a density of $6500 \mathrm{~kg} / \mathrm{m}^{3}, 4250$ $\mathrm{kg} / \mathrm{m}^{3}$ and $2200 \mathrm{~kg} / \mathrm{m}^{3}$, mass fraction of $0.06 \%$ and particle diameter of $45 \mathrm{~nm}$. Also, pure R134a refrigerant will be used as the base fluid. Due to the limited number of studies regarding the experimental study of Nano refrigerants, Subramani and Prakash's experimental database [5] will be used in the validation process of the proposed model. The density of a Nano refrigerant can be a parameter to obtain the enthalpy of working fluid. Mollier charts of pure refrigerant can be used to obtain enthalpy values corresponding to the density and 
temperature or pressure at cycle point, so there is no chart or correlation to predict the properties of Nano refrigerants. It should be noted that the enthalpy of point 3 is estimated as follows. First, temperature $\left(T_{\mathrm{PR} 3}\right)$ and saturation pressure ( $\left.P_{\mathrm{PR} 3}\right)$ corresponding to $T_{\mathrm{PR} 3}$ are specified at $45.6^{\circ} \mathrm{C}$ and $11.8 \mathrm{bar}$, respectively. Then density is read from the Mollier chart of R134a. Density of Nano refrigerant $\left(\rho_{\mathrm{NR}}\right)$ is calculated by replacing nanoparticle mass fraction in Nano refrigerant $\left(\omega_{\mathrm{n}}\right), \rho_{\mathrm{NP}}$ and $\rho_{\mathrm{PR}}$ in the density equation with their respective values. Then saturation temperature and pressure and enthalpy of Nano refrigerant are read from chart R134a for point 3. Enthalpy at point 3 decreases to $116.49 \mathrm{~kJ} / \mathrm{kg}$ from $116.73 \mathrm{~kJ} / \mathrm{kg}$.

Similar to the determination of enthalpy of Nano refrigerant at point 3, enthalpy of nanorefrigerant at point 1 can be found. Temperature $\left(T_{\mathrm{PR} 1}\right)$ and saturation pressure $\left(P_{\mathrm{PR} 1}\right)$ corresponding to $T_{\mathrm{PR} 1}$ is specified at $-7^{\circ} \mathrm{C}$ and 2.25 bar, respectively. Then density is read from the chart of R134a. The density of Nano refrigerant $\left(\rho_{\mathrm{NR}}\right)$ is calculated by replacing nanoparticle mass fraction in Nano refrigerant $(\omega), \rho_{\mathrm{NP}}$, and $\rho_{\mathrm{PR}}$ in the density equation with their respective values. Then saturation temperature and pressure and the enthalpy of the Nano refrigerant are read from chart R134a for point 1. Enthalpy at point 1 (using $\mathrm{Al}_{2} \mathrm{O}_{3}$ ) increases to $249.32 \mathrm{~kJ} / \mathrm{kg}$ from $245.87 \mathrm{~kJ} / \mathrm{kg}$. Further, enthalpy of Nano refrigerant at point 2 and 4 can be found using the specifications given at state 3 such as pressure and temperature. Temperature $\left(T_{\mathrm{PR} 2}\right)$ at state 2 is specified at $81.5^{\circ} \mathrm{C}$ while the pressure $\left(P_{\mathrm{PR} 2}\right)$ is 11.8 bar, since condensation is at constant pressure. Then density is read from the chart of R134a. The density of Nano refrigerant $\left(\rho_{\mathrm{NR}}\right)$ is calculated by replacing nanoparticle mass fraction in Nano refrigerant $(\omega), \rho_{\mathrm{NP}}$, and $\rho_{\mathrm{PR}}$ in the density equation with their respective values. Then saturation temperature and pressure and the enthalpy of the Nano refrigerant are read from chart R134a for point 2. Enthalpy at point 1 decreases to $312.57 \mathrm{~kJ} / \mathrm{kg}$ from $312.99 \mathrm{~kJ} / \mathrm{kg}$. At state 4 , the enthalpy is equal to that of state 3 since process 3 - 4 is adiabatic. As for the isentropic work of the compressor, $h_{2 \mathrm{~s}}$ is read from the chart by making use of $s_{1}$ and saturation pressure at point 3 . The isentropic work is found to be $35.51 \mathrm{~kJ} / \mathrm{kg}$ for pure refrigerant. At the outlet of the compressor, if isentropic efficiency is 1 and the refrigeration cycle is ideal, $s_{1}$ and $s_{2}$ must be equal. For this calculation, isentropic efficiency is 0.53. COP enhancement is $9.38 \%$. Table 1 represents corresponding properties and results for the cycle working with $\mathrm{R} 134 \mathrm{a}$ and $\mathrm{R} 134 \mathrm{a} / \mathrm{Al}_{2} \mathrm{O}_{3}$.

The $\mathrm{Al}_{2} \mathrm{O}_{3}$ nanoparticle can be produced in a wide range of densities using recent techniques, thus, in this work, we take the density of $\mathrm{Al}_{2} \mathrm{O}_{3}$ nanoparticle as $2200 \mathrm{~kg} / \mathrm{m}^{3}$. The results of our calculation approximate those of Subramani and Prakash [5] results with $82 \%$ accuracy, despite the authors assuming $\mathrm{Al}_{2} \mathrm{O}_{3}$ density of $3690 \mathrm{~kg} / \mathrm{m}^{3}$. Some results from Subramani and Prakashexperimental study [5] for the validation process of the current study can be seen in Table 3 and Figure 2 .

Table 3 Some results from experimental study [5] for the validation of the current model.

Thus, for the purpose of our main study which is the numerical simulation 
Table 1. Corresponding properties and developed model's results for the cycle working with $\mathrm{R} 134 \mathrm{a}$ and $\mathrm{R} 134 \mathrm{a} / \mathrm{Al}_{2} \mathrm{O}_{3}$.

\begin{tabular}{ccccc}
\hline Properties & $\begin{array}{c}\mathrm{PR} \\
(\mathrm{R} 134 \mathrm{a})\end{array}$ & $\begin{array}{c}\mathrm{NR} 1 \\
\left(\mathrm{R} 134 \mathrm{a} / \mathrm{Al}_{2} \mathrm{O}_{3}\right)\end{array}$ & $\begin{array}{c}\mathrm{NR} 2 \\
(\mathrm{R} 134 \mathrm{a} / \mathrm{CUO})\end{array}$ & $\begin{array}{c}\mathrm{NR} 3 \\
\left(\mathrm{R} 134 \mathrm{a} / \mathrm{TiO}_{2}\right)\end{array}$ \\
\hline$P_{1}=P_{4}(\mathrm{bar})$ & 2.2 & 2.74 & 2.99 & 2.47 \\
$T_{1}\left({ }^{\circ} \mathrm{C}\right)$ & -7.7 & -1.93 & 0.48 & -4.6 \\
$T_{2}\left({ }^{\circ} \mathrm{C}\right)$ & 81.5 & 81.1 & 66.73 & 71.45 \\
$T_{3}\left({ }^{\circ} \mathrm{C}\right)$ & 45.6 & 45.45 & 44.84 & 45.1 \\
$P_{3}=P_{2}(\mathrm{bar})$ & 11.8 & 11.76 & 11.58 & 11.67 \\
$h_{1}(\mathrm{~kJ} / \mathrm{kg})$ & 245.87 & 249.32 & 250.73 & 247.73 \\
$h_{2}(\mathrm{~kJ} / \mathrm{kg})$ & 312.99 & 312.57 & 297.03 & 302.178 \\
$h_{3}=h_{4}(\mathrm{~kJ} / \mathrm{kg})$ & 116.73 & 116.49 & 115.58 & 116.06 \\
$s_{1}(\mathrm{~kJ} / \mathrm{kg} \mathrm{K})$ & 0.9362 & & & \\
$q_{c}(\mathrm{~kJ} / \mathrm{kg})$ & 205.26 & 196.08 & 181.45 & 186.12 \\
$q_{e}(\mathrm{~kJ} / \mathrm{kg})$ & 129.14 & 132.83 & 135.15 & 131.67 \\
$W_{\text {comp }}(\mathrm{kJ} / \mathrm{kg})$ & 67.12 & 63.25 & 46.3 & 54.45 \\
$\mathrm{C} . \mathrm{O} . \mathrm{P}$ & 1.92 & 2.1 & 2.9 & 2.4 \\
$\eta_{\text {ise }}$ & 0.53 & & & \\
\hline
\end{tabular}

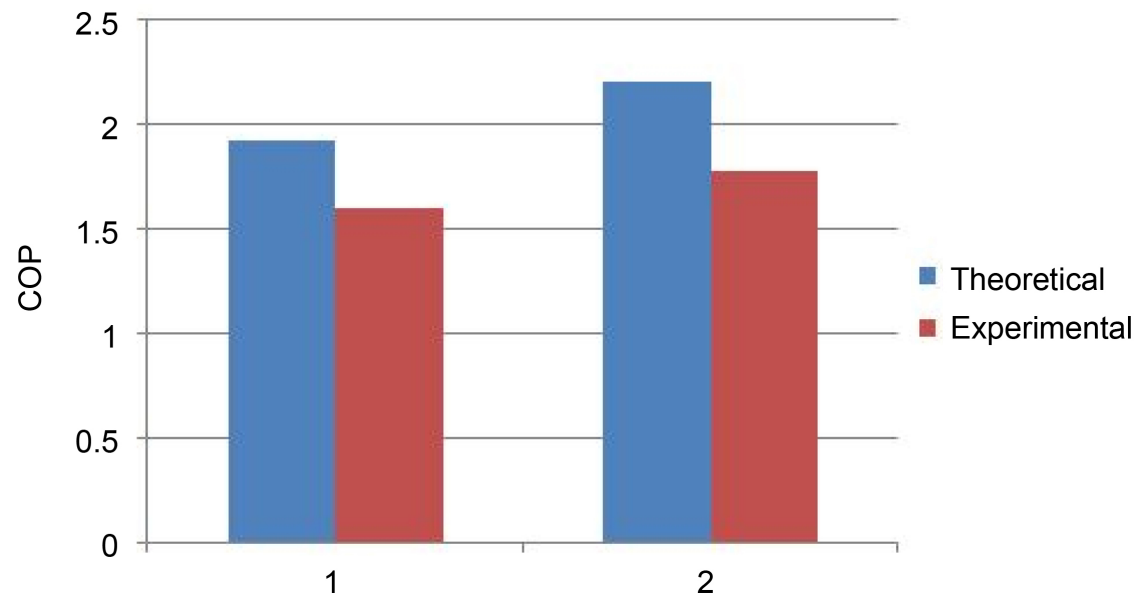

Figure 2. Comparison of experimental and theoretical COPs for R134a and $\mathrm{R} 134 \mathrm{a} / \mathrm{Al}_{2} \mathrm{O}_{3}$.

and performance assessment of a nanoparticle enhanced vapor compression refrigeration system, we propose a model of a vapor compression refrigeration system with three different nano refrigerants as the working fluid with state point properties as shown in the last three columns of Table 1 above. The corresponding properties and the results for the cycle working with R134a and $\mathrm{R} 134 \mathrm{a} / \mathrm{Al}_{2} \mathrm{O}_{3}$ which serve as the baseline or reference are shown in Table 2.

\section{Numerical Simulation}

The simulation was performed with a package in REFPROP software called Coolprop. REFPROP is an acronym for Reference fluid Properties. This program, 
Table 2. Corresponding properties and literature results [5] for the cycle working with $\mathrm{R} 134 \mathrm{a}$ and $\mathrm{R} 134 \mathrm{a} / \mathrm{Al}_{2} \mathrm{O}_{3}$.

\begin{tabular}{cccccccccc}
\hline Cycle fluid & $T_{1}\left({ }^{\circ} \mathrm{C}\right)$ & $\begin{array}{c}\rho_{P} \\
\left(\mathrm{~kg} / \mathrm{m}^{3}\right)\end{array}$ & $\begin{array}{c}P_{1} \\
(\mathrm{bar})\end{array}$ & $T_{2}\left({ }^{\circ} \mathrm{C}\right)$ & $T_{3}\left({ }^{\circ} \mathrm{C}\right)$ & $P_{3}(\mathrm{bar})$ & $\begin{array}{c}\text { C.O.P } \\
(+)\end{array}$ & $\%(-)$ & $\%$ \\
\hline $\begin{array}{c}\text { R134a (exp) } \\
\text { R134a/ } \mathrm{Al}_{2} \mathrm{O}_{3}\end{array}$ & 19 & & 2 & 82 & 45 & 12 & 1.6 & & \\
$\quad(\mathrm{exp})$ & & 3690 & 2 & 80 & 38 & 12 & 1.78 & 10.11 & \\
Current (R134a) & -7.7 & & 2.2 & 81.5 & 45.6 & 11.8 & 1.92 & & 20 \\
Current (NR1) & -1.93 & 2200 & 2.74 & 81.1 & 45.45 & 11.76 & 2.1 & 9.4 & 18 \\
Current (NR2) & 0.48 & 6500 & 2.99 & 66.73 & 44.84 & 11.58 & 2.9 & 51.1 & \\
Current (NR3) & -4.6 & 4250 & 2.47 & 71.45 & 45.10 & 11.67 & 2.4 & 25 & \\
\hline
\end{tabular}

developed by the National Institute of Standards and Technology (NIST), calculates the thermodynamic and transport properties of industrially important fluids and their mixtures. The Cool prop is a package in REFPROP that has a dynamic library through which it runs its $\mathrm{C}++$ encoded equations of states to get thermodynamic and thermo physical properties of states. It can be used on different programming platforms like MATLAB and FORTRAN. In this work, it was used on a MATLAB platform via python. In the first part of the simulation, the mass fraction of nanoparticles were varied from $0.06 \%$ to $0.6 \%$ on a mesh of ten equally spaced points. A constant nanoparticle size of about $45 \mathrm{~nm}$ was maintained for all the nanoparticles while a constant densities of $2200 \mathrm{~kg} / \mathrm{m}^{3}$, $6500 \mathrm{~kg} / \mathrm{m}^{3}$ and $4250 \mathrm{~kg} / \mathrm{m}^{3}$ were maintained for the $\mathrm{AL}_{2} \mathrm{O}_{3}, \mathrm{CUO}$ and $\mathrm{TiO}_{2}$ nanoparticles, respectively. The variations of the mass fraction with system properties and performance were carefully observed and plotted. In the second part, the densities of each nanoparticles were varied on a step of $5 \mathrm{~kg} / \mathrm{m}^{3}$ with a constant mass fraction of $0.06 \%$. Recent studies and techniques have shown that nanoparticles can be manufactured at different densities and the higher the density the higher the particle size diameter. Thus, the nanoparticle sizes were indirectly varied by density. In all the two simulation cases, the condenser pressure was maintained at $1.18 \mathrm{MPa}$ and the evaporator pressure is $0.22 \mathrm{MPa}$ and no appreciable pressure drops due to friction were assumed in the condenser and evaporator. After all the simulations, the results were plotted and validation was carried out using Subramani and Prakash's experimental study as our basis of comparison in terms of COP [5]. Thereafter, deductions were made and these were extensively discussed in the next chapter.

\section{Results and Discussion}

In this work, we have studied the effects of mass fractions and densities of three different nanoparticles namely; $\mathrm{Al}_{2} \mathrm{O}_{3}, \mathrm{CUO}$ and $\mathrm{TiO}_{2}$ in a single $\mathrm{R} 134 \mathrm{a}$ refrigerant on the properties and performance of a vapour compression refrigeration system. The model of the vapour compression refrigeration system was formulated by specifications using Subramani and Prakash's experimental study [5] as the basis. The model was then simulated using the flow chart in Figure 3 on a 


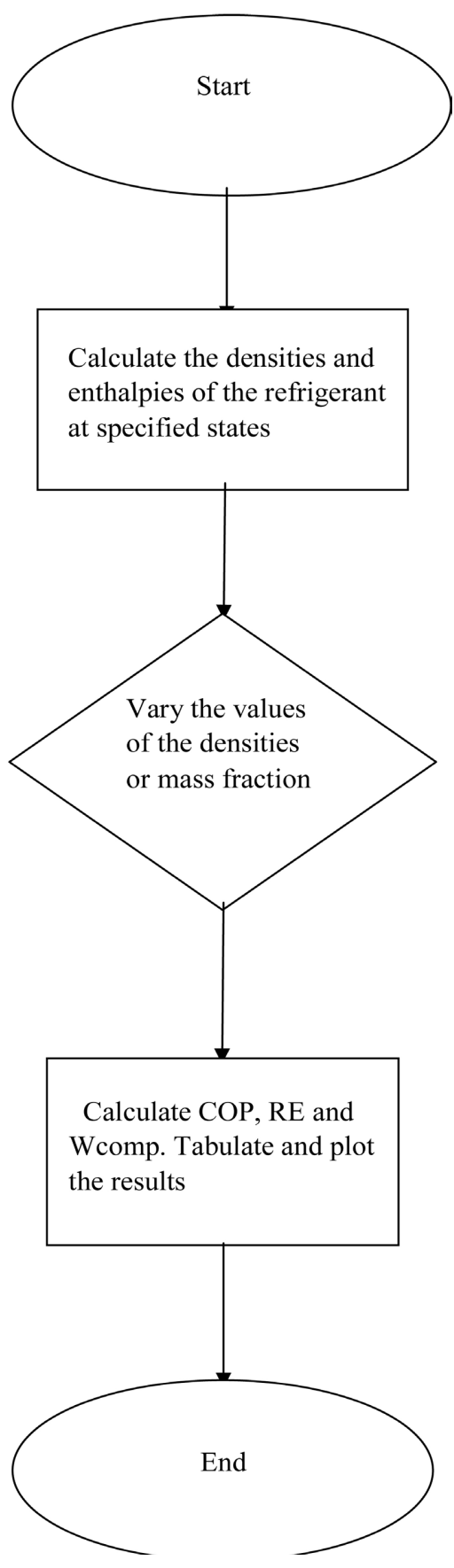

Figure 3. Flow chart.

MATLAB platform with a CoolProp thermodynamic library already installed via python. Constant densities were maintained for all three nanoparticles while mass fractions were varied at a step of $0.067 \%$ in the first phase of simulation while the mass fraction of $0.06 \%$ was maintained in the second part of the simulation and the densities were varied at a step of $5 \mathrm{~kg} / \mathrm{m}^{3}$. The results which reflect the various effects of mass fraction and density of nanoparticles on the properties of a vapor compression refrigeration system working with the nano refrigerants are presented in graphical form and extensively discussed in this section. 


\subsection{Validation}

I considered testing for the accuracy and validity of the results by making a comparison between my results and that of the Subramani and Prakash's experimental study as shown in the histogram presented in the next page.

The first two bars of the histogram represent the COP for the pure refrigerant $\mathrm{R} 134 \mathrm{a}$ while the other bars correspond to $\mathrm{R} 134 \mathrm{a} / \mathrm{Al}_{2} \mathrm{O}_{3}$ nano refrigerant. It can be observed that the COP of the pure refrigerant R134a from our theoretical results compares favourably well with that of the [5] Subramani and Prakash's experimental study with a minimal deviation of about $20 \%$ while that of the nano refrigerant $\mathrm{R} 134 \mathrm{a} / \mathrm{Al}_{2} \mathrm{O}_{3}$ is also in good agreement with a deviation of about $18 \%$. This is also shown on Table 3 as shown below. This has shown that the MATLAB code written for this numerical analysis is giving correct and valid results and it can be used for further analysis in this work.

\subsection{Effects of Mass Fraction on System Properties and Performance}

The effects of mass fraction of the nanoparticles on various system properties and performance are illustrated in Figures 4-6 shown in the next pages.

As shown in Figure 4 below, the refrigerating effect increases as the mass fraction advances for the three nano refrigerants. This is due to the fact that more nanoparticles are present per unit of mass of the refrigerant and this significantly increases the heat transfer coefficient of the refrigerant thereby increasing the refrigerating effect. Also, in Figure 5 shown below, the compressor work diminishes as the mass fraction enhances for the three nano refrigerants. The movement of the nanoparticle within the nano refrigerant contributes to the pressure of the nano refrigerant thereby leaving less work for the compressor to attain the desired condenser pressure. Thus, this makes the amount of work required by the compressor to decrease significantly. However, the compressor work cannot fall below zero as shown in the figure in a practical sense. The practicable interpretation of this is that the compressor will stop working at a mass fraction value beyond $0.2 \%$ for $\mathrm{R} 134 \mathrm{a} / \mathrm{CUO}$ and $0.3 \%$ for $\mathrm{R} 134 \mathrm{a} / \mathrm{TiO}_{2}$. As for the $\mathrm{R} 134 \mathrm{a} / \mathrm{Al}_{2} \mathrm{O}_{3}$, the compressor will not stop working for all the mass fraction values investigated.

Lastly, Figure 6 shown below is the effect of mass fraction on system's performance. Since the coefficient of performance (COP) is the ratio of the refrigerating effect to the compressor work, the overall effect is that the COP increases as mass fraction increases. The COPs of the system with R134a/CUO and $\mathrm{R} 134 \mathrm{a} / \mathrm{TiO}_{2}$ fell below positive values due to the negative values of the compressor work. The effects of density of the nanoparticles on the system's refrigerating

Table 3. Comparison of COP for R134a and R134a/ $/ \mathrm{Al}_{2} \mathrm{O}_{3}$.

\begin{tabular}{cccc}
\hline & $\mathrm{R} 134 \mathrm{a}$ & $\mathrm{R} 134 \mathrm{a} / \mathrm{Al}_{2} \mathrm{O}_{3}$ & Deviation \\
\hline Experimental COP & 1.6 & 1.78 & $20 \%$ \\
Theoretical COP & 1.92 & 2.1 & $18 \%$ \\
\hline
\end{tabular}




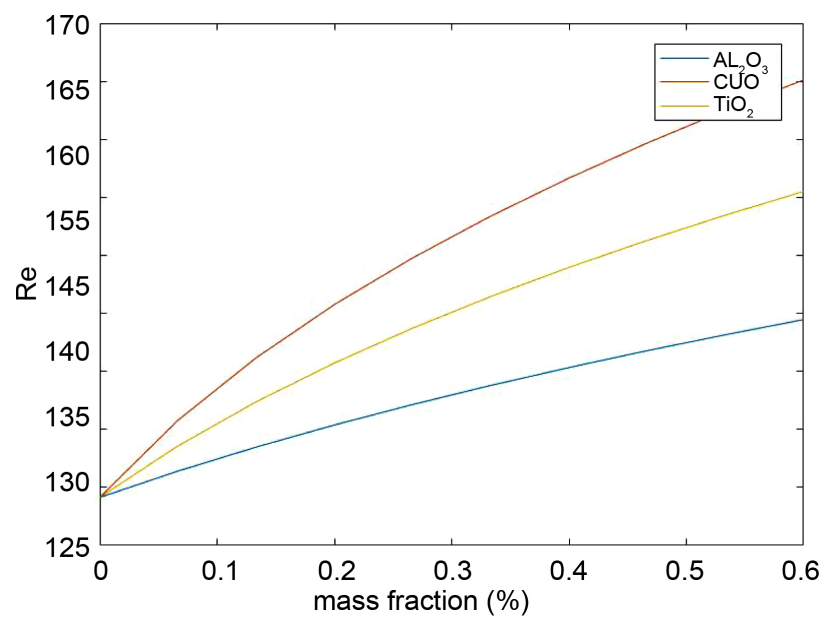

Figure 4. Effects of mass fraction of nanoparticles on the refrigerating effect (RE).

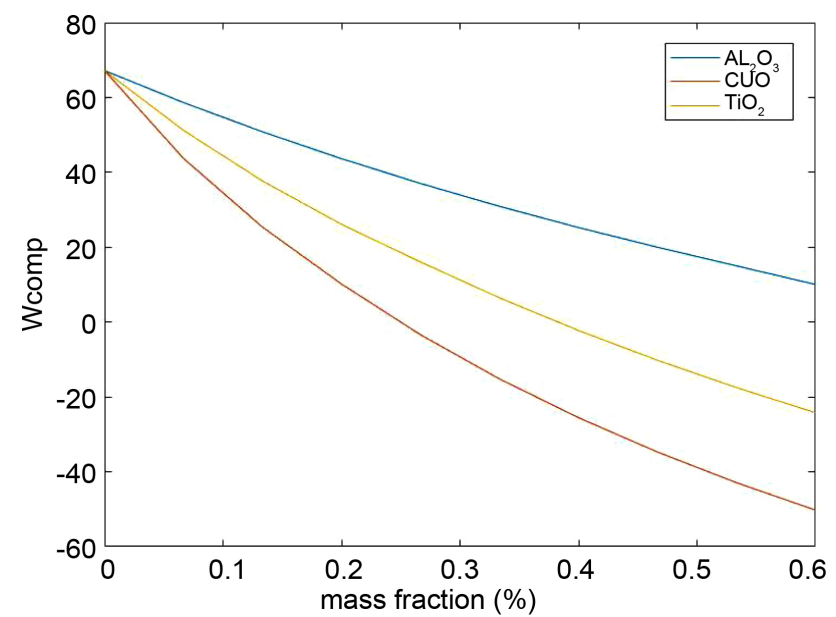

Figure 5. Effects of mass fraction of nanoparticles on the compressor work (Wcomp).

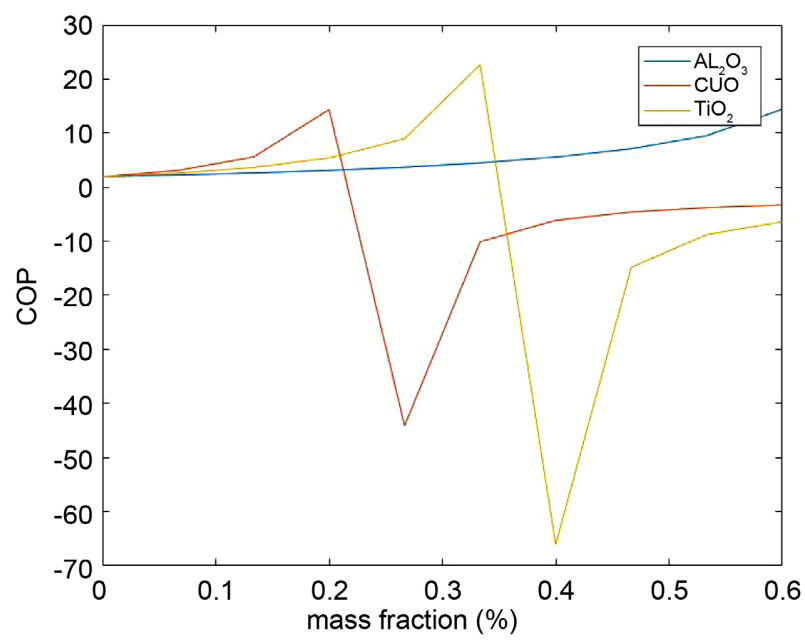

Figure 6. Effects of mass fraction of nanoparticles on coefficient of performance (COP). 
effect are illustrated in Figures 7-9 shown below.

As shown in the Figures 7-9 below, the refrigerating effect enhances significantly as the density of all the nanoparticles increase. This is due to the fact that nanoparticles have large radius at high densities and this gives them large surface areas for enhanced heat transfer qualities. Consequently, the refrigerating effect advances linearly with the densities.

\subsection{Compressor Work (Wcomp)}

The effects of density of the nanoparticles on the system's compressor work are illustrated in Figures 10-12 shown below.

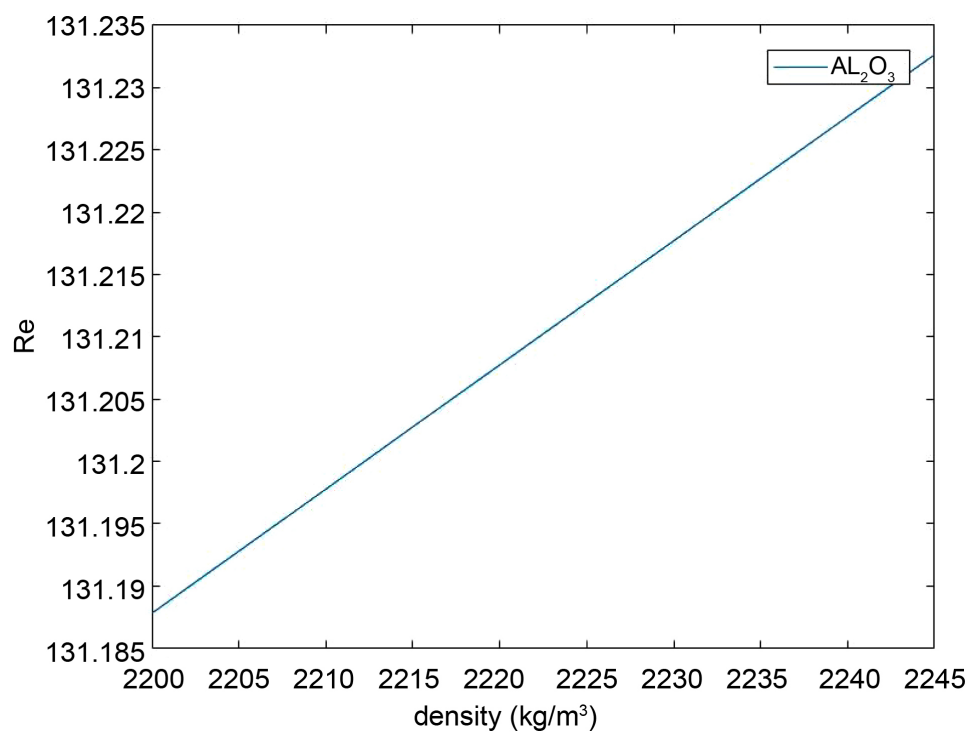

Figure 7. Effects of density of $\mathrm{Al}_{2} \mathrm{O}_{3}$ nanoparticle on refrigerating effect (RE).

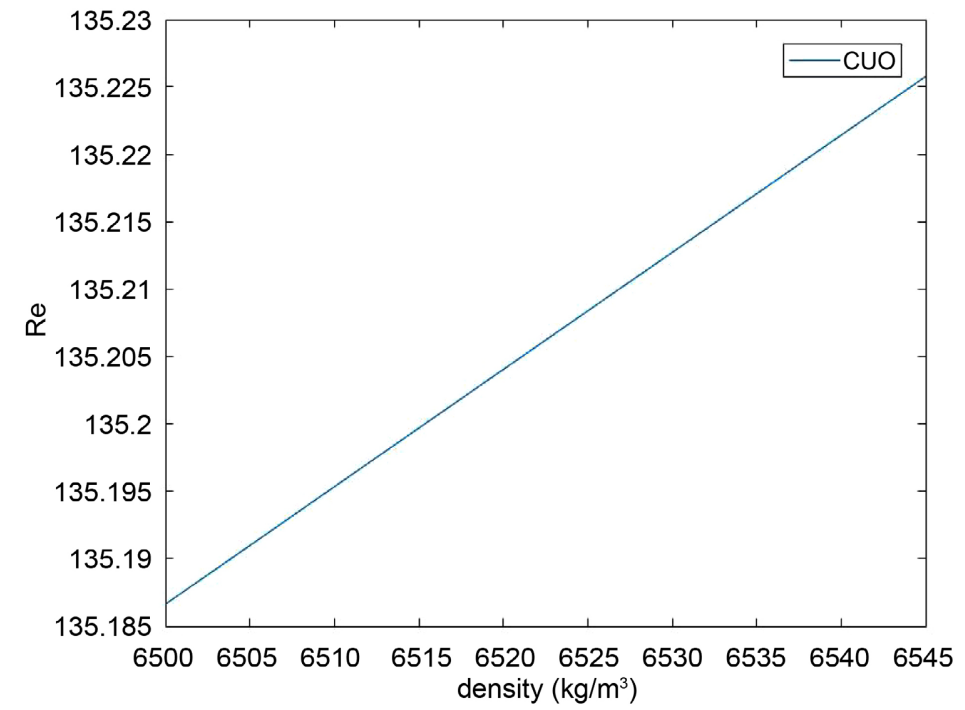

Figure 8. Effects of density of CUO nanoparticle on refrigerating effect (RE). 


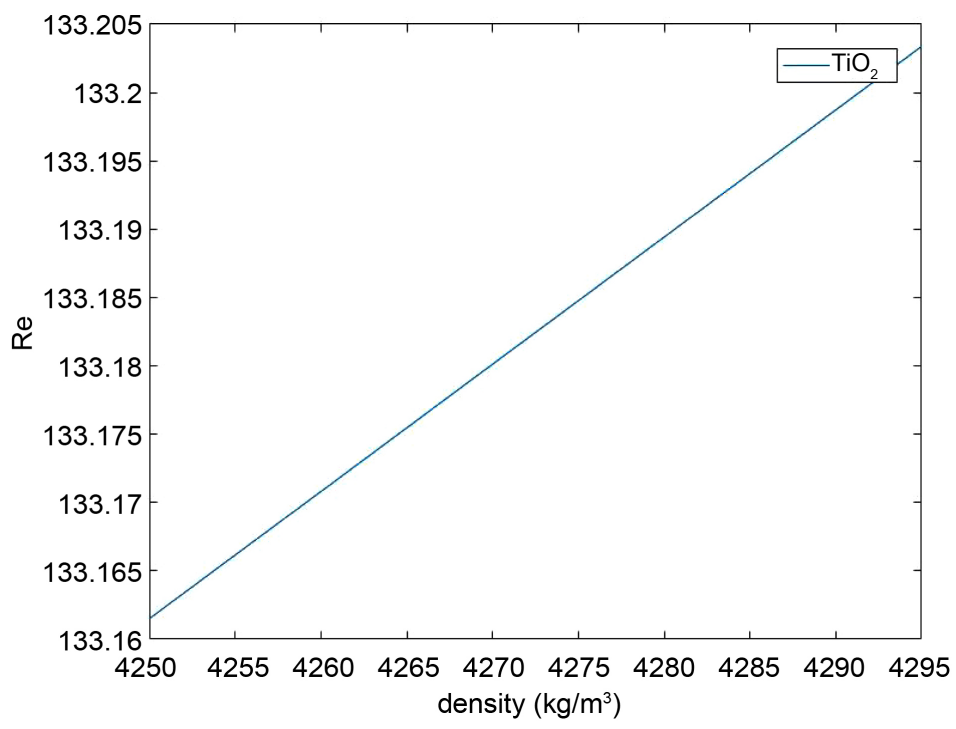

Figure 9. Effects of density of $\mathrm{TiO}_{2}$ nanoparticle on refrigerating effect (RE).

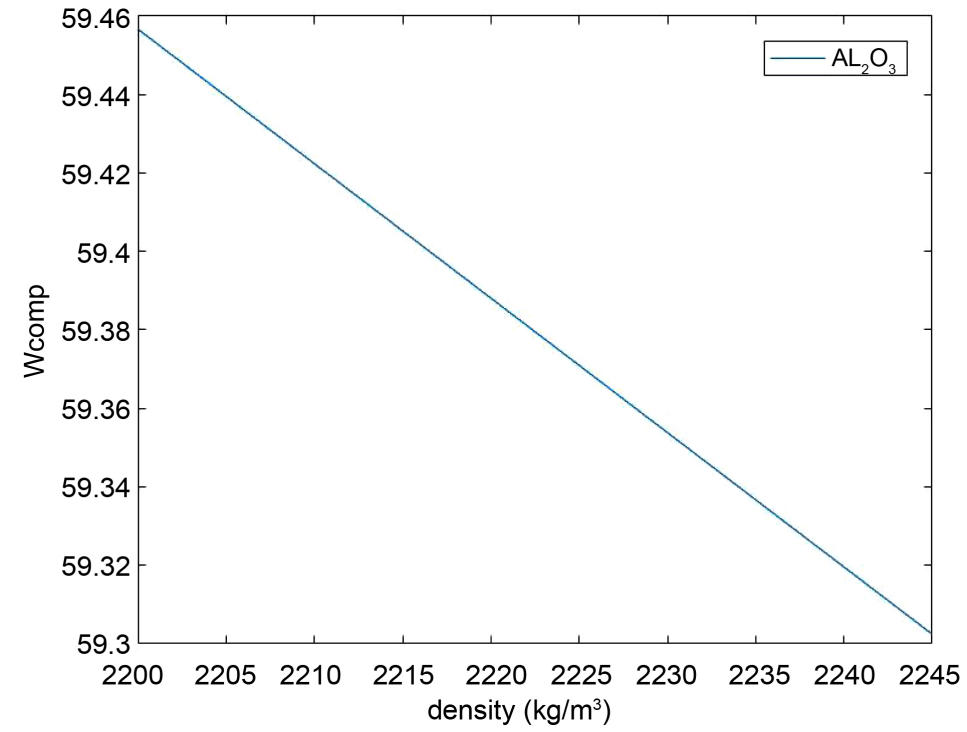

Figure 10. Effects of density of $\mathrm{Al}_{2} \mathrm{O}_{3}$ nanoparticle on compressor work (Wcomp).

As shown in the Figures 10-12 above, the compressor work decreases linearly as the density of all the nanoparticles increase. This is because, the movement of highly density nanoparticles largely within the nano refrigerants largely contributes to the pressure of the nano refrigerants. Thus, lesser compressor work would be required to attain the desired condenser pressure.

\subsection{Coefficient of Performance (COP)}

The effects of density of the nanoparticles on the system's coefficient of performance are illustrated in Figures 13-15 shown below.

Finally, as shown in Figures 13-15 below, the overall effect of the increase 


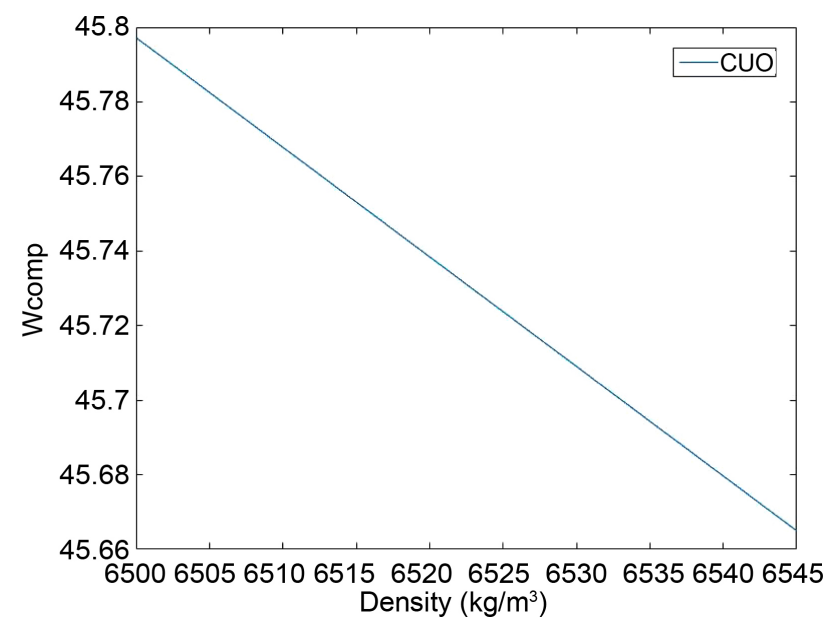

Figure 11. Effects of density of CUO nanoparticle on compressor work (Wcomp).

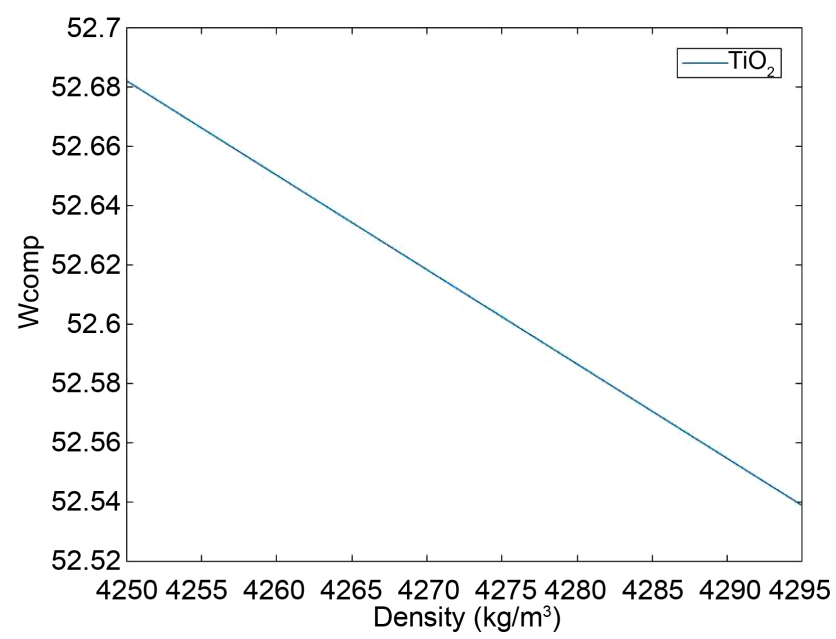

Figure 12. Effects of density of $\mathrm{TiO}_{2}$ nanoparticle on compressor work (Wcomp).

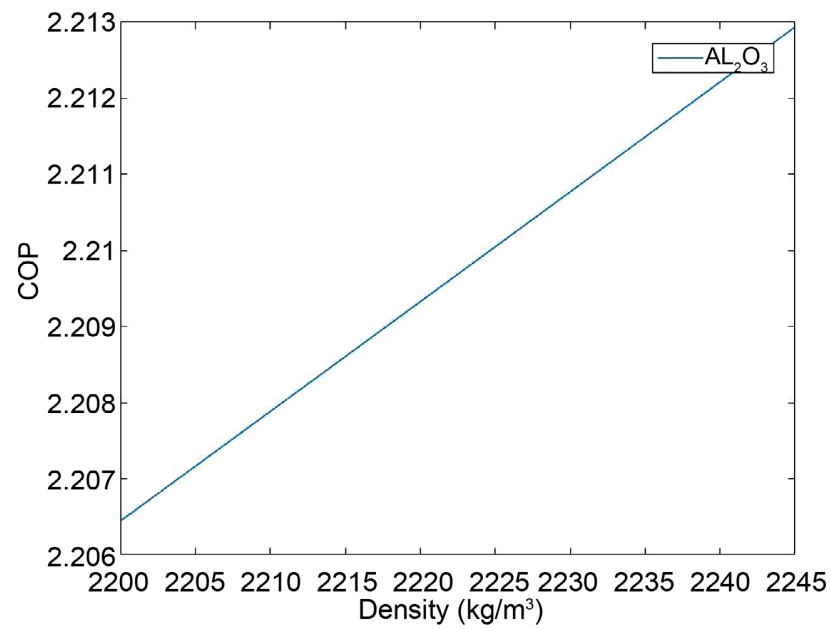

Figure 13. Effects of density of $\mathrm{Al}_{2} \mathrm{O}_{3}$ nanoparticle on system's performance (COP). 


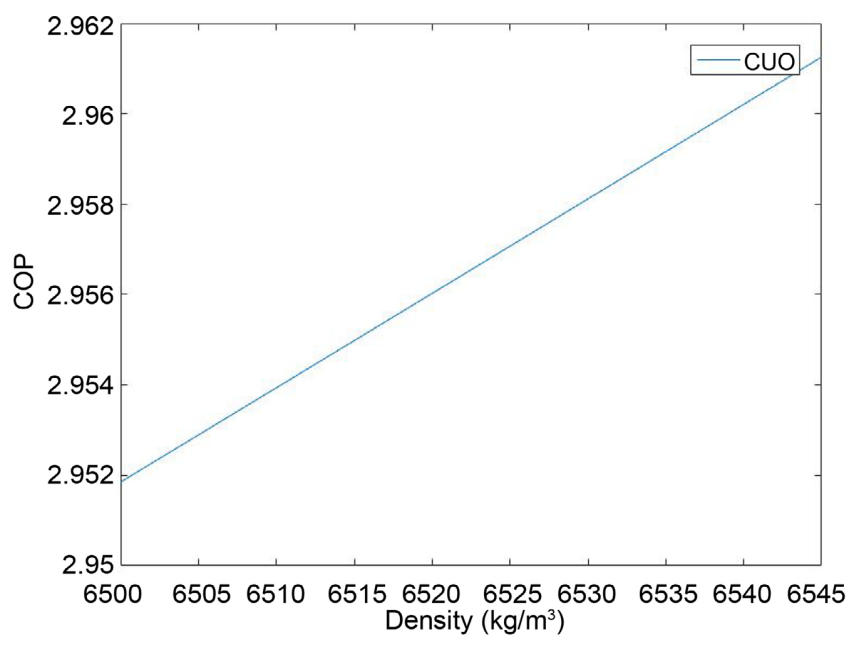

Figure 14. Effects of density of CUO nanoparticle on system's performance (COP).

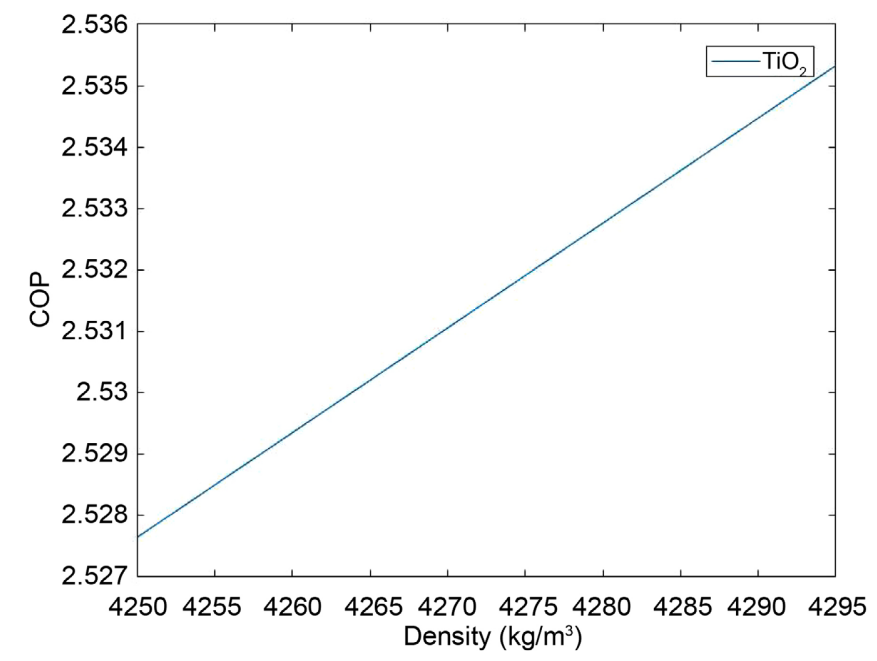

Figure 15. Effects of density of $\mathrm{TiO}_{2}$ nanoparticle on system's performance (COP).

Table 4. Variation of COP with the Alumina nanoparticle density.

\begin{tabular}{cc}
\hline Density $\left(\mathrm{Al}_{2} \mathrm{O}_{3}\right)$ & COP \\
2200.0000 & 2.2064 \\
2205.0000 & 2.2072 \\
2210.0000 & 2.2079 \\
2215.0000 & 2.2086 \\
2220.0000 & 2.2093 \\
2225.0000 & 2.2093 \\
2230.0000 & 2.2108 \\
2235.0000 & 2.2115 \\
2240.0000 & 2.2122 \\
2245.0000 & 2.2129 \\
\hline
\end{tabular}


Table 5. Variation of COP with the CUO nanoparticle density.

\begin{tabular}{cc}
\hline Density (CUO) & COP \\
\hline 6500.0000 & 2.9519 \\
6505.0000 & 2.9529 \\
6510.0000 & 2.9539 \\
6515.0000 & 2.9550 \\
6520.0000 & 2.9560 \\
6525.0000 & 2.9571 \\
6530.0000 & 2.9581 \\
6535.0000 & 2.9592 \\
6540.0000 & 2.9602 \\
6545.0000 & 2.9613 \\
\hline
\end{tabular}

Table 6. Variation of COP with the $\mathrm{TiO}_{2}$ nanoparticle density.

\begin{tabular}{cc}
\hline Density $\left(\mathrm{TiO}_{2}\right)$ & COP \\
4250.0000 & 2.5276 \\
4255.0000 & 2.5285 \\
4260.0000 & 2.5293 \\
4265.0000 & 2.5302 \\
4270.0000 & 2.5311 \\
4275.0000 & 2.5319 \\
4280.0000 & 2.5328 \\
4285.0000 & 2.5336 \\
4290.0000 & 2.5345 \\
4295.0000 & 2.5353 \\
\hline
\end{tabular}

and decrease of refrigerating effect and compressor work respectively is that the $\mathrm{COP}$ increases as the densities of all the nanoparticles increase. All these are also illustrated in the given Tables 4-6 above.

\section{Conclusions}

In the present work, we have developed a numerical model for the simulation of nanoparticle enhanced vapor compression refrigeration system and we have carried out the performance assessment of the system. The results of the investigation established the followings:

Both the refrigerating effect and the COP of the system increase as the mass fraction of all the nanoparticles increases.

* The compressor work decreases as the mass fraction of all the nanoparticles increased.

* The refrigerating effect and the COP of the system increase as the density of all the nanoparticles are increased. 
The compressor work decreases as the density of all the nanoparticles increased.

* Generally from these results, it can be concluded that more works still need to be done to investigate the effects of other properties of nanoparticles on a vapour compression refrigeration system as this aspect is of utmost importance in engineering field.

\section{Conflicts of Interest}

The authors declare no conflicts of interest regarding the publication of this paper.

\section{References}

[1] Taiwo, O.B., Daniel, M.M. and Stephen, A.A. (2018) Enhancing the Performance of Vapour Compression Refrigeration System Using Nano Refrigerants: A Review. Conference Series Materials Science and Engineering, 413, Article ID: 012068. https://doi.org/10.1088/1757-899X/413/1/012068

[2] Pitchia, K.B., Gokulnath, K., Vijayan, R. and Vivek, S. (2019) Experimental Analysis of Vapour Compression Refrigeration System by Using Nano Refrigerant (R290/ R600a/ $\mathrm{Al}_{2} \mathrm{O}_{3}$ ). AIP Conference Proceedings, 2128, Article ID: 050023.

[3] Nair, P., Parekh, A.D. and Tailor, P.R. (2020) Experimental Investigation of Vapour Compression Refrigeration System Using R134a/Nano-Oil Mixture. International Journal of Refrigeration, 112, 21-36. https://doi.org/10.1016/j.ijrefrig.2019.12.009

[4] Senthilkumar, A., Anderson, A. and Sekar, M. (2021) Performance Analysis of R600a Vapour Compression Refrigeration System Using $\mathrm{CuO} / \mathrm{Al}_{2} \mathrm{O}_{3}$ Hybrid Nanolubricants. Applied Nanoscience. https://doi.org/10.1007/s13204-021-01936-y

[5] Subramani, N. and Prakash, M.J. (2011) Experimental Studies on a Vapour Compression System Using Nanorefrigerants. International Journal of Engineering, Science and Technology, 3, 95-102. https://doi.org/10.4314/ijest.v3i9.8

[6] Sajumon, K.T., Sree, J., Jubin, V.J. and Sreeraj, K.P.N. (2013) Performance Analysis of Engineering and Technology. International Journal of Innovative Research in Science, Engineering and Technology, 2, 832-838.

[7] Babatunde, T.O., Akinlabi, S.A. and Madyira, D.M. (2020) Energy Performance Evaluation ofR600a/MCNT-Nanolubricant as a Drop-in Replacement for R134a in Household Refrigerator System. Energy Reports, 6, 639-647.

https://doi.org/10.1016/j.egyr.2019.11.132

[8] Babatunde, T.O., Akinlabi, S.A., Madyira, D.M. and Ekundayo, F.M. (2020) Enhancing the Energy Efficiency of Vapour Compression Refrigerator System Using R600a with Graghene Nanolubricant. Energy Reports, 6, 1-10. https://doi.org/10.1016/j.egyr.2019.11.031

[9] Kedzierski, M.A. (2012) Effect of Diamond Nanolubricant on R134a Pool Boiling Heat Transfer. Journal of Heat Transfer, 134, Article ID: 051001. https://doi.org/10.1115/1.4005631

[10] Juan, L.C.V., Pruzaesky, F.C. and Parise, J.A.R. (2010) A Numerical Study on the Application of Nanofluids in Refrigeration Systems. International Refrigeration and Air Conditioning Conference, Lafayette, 12-15 July 2010, 1-10. 